\title{
Expression of GLP-1 receptor and CD26 in human thyroid C-cells: The association of thyroid C-cell tumorigenesis with incretin-based medicine
}

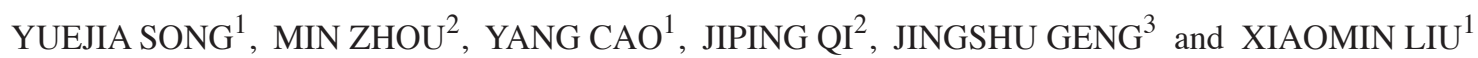 \\ Departments of ${ }^{1}$ Endocrinology and ${ }^{2}$ Pathology, The First Hospital of Harbin Medical University; \\ ${ }^{3}$ Department of Pathology, The Third Hospital of Harbin Medical University, Harbin, Heilongjiang 150001, P.R. China
}

Received August 8, 2015; Accepted December 20, 2016

DOI: $10.3892 / \mathrm{ol} .2017 .5752$

\begin{abstract}
Recent reports have demonstrated that long-term and high dosage treatments with incretin-based medicine, such as hormone glucagon-like peptide-1 (GLP-1) may induce thyroid C-cell pathological changes in rodents, rather than in humans. Doubts regarding the tumorigenic potential of GLP-1 analogues in human thyroid $\mathrm{C}$-cells remain. The present study aimed to determine the expression levels of GLP-1 receptor (GLP-1R) and cluster of differentiation 26 (CD26) in the C-cells of thyroid tissues from non-neoplastic, medullary carcinoma and hyperplasia subjects, and to explore the potential clinical significance. The following cases were analyzed: Medullary thyroid carcinoma $(n=62$, including 59 paraffin-embedded samples and 3 fresh frozen samples), C-cell hyperplasia $(n=20$, paraffin-embedded samples) and non-neoplastic thyroid tissue samples ( $\mathrm{n}=7$, paraffin-embedded samples). GLP-1R and CD26 expression was detected using immunohistochemical staining and western blotting. There were significant differences in the expression levels of the two markers between medullary thyroid carcinoma and C-cell hyperplasia, in addition to between medullary thyroid carcinoma and non-neoplastic thyroid tissue following immunohistochemical staining. Similar significant differences in the expression of GLP-1R and CD26 were detected using western blot analysis in the medullary thyroid carcinoma compared with non-neoplastic thyroid tissue sectioned from the aforementioned fresh frozen samples. There was a significant negative correlation between GLP-1R and CD26 expression. In addition, the present data indicated that GLP-1R expression was associated with the age
\end{abstract}

Correspondence to: Professor Xiaomin Liu, Department of Endocrinology, The First Hospital of Harbin Medical University, 23 Youzheng Street, Nangang, Harbin, Heilongjiang 150001, P.R. China

E-mail: 1344230@qq.com

Key words: medullary thyroid cancer, glucagon-like peptide-1 receptor, cluster of differentiation 26, thyroid C-cell of the patients with medullary thyroid carcinoma. These results suggested that GLP-1R and CD26 may be closely associated with the development of thyroid $\mathrm{C}$-cell hyperplasia and medullary thyroid carcinoma, and indicated the importance of being aware of the side effects of incretin medicine.

\section{Introduction}

Glucagon-like peptide-1 (GLP-1) analogues and cluster of differentiation 26 (CD26) inhibitors belong to a class of medicines based on incretin, which have been extensively used in the treatment of type 2 diabetes. GLP-1 receptor (GLP-1R) is a $G$ protein-coupled receptor that is widely expressed in the human body, and mediates the tumorigenesis of several types of cancer (1). Animal experiments have demonstrated that long-term GLP-1 treatment may induce thyroid hyperplasia, hypercalcitoninemia or even carcinomatous changes (2). Although previous studies have indicated that there is little or no GLP-1R expression in human thyroid C-cells $(2,3)$, controversy remains regarding the safety of GLP-1 analogues used as anti-diabetic drugs or combined with the use of other drugs, such as proton-pump inhibitors (PPIs). This controversy is mainly due to the shortage of results regarding C-cell morphological changes during or after long-term and/or large dosage GLP-1 analogue treatment. CD26 is associated with inflammation, infection, tumor biology and the enzymatic activity of GLP-1; in addition, it is also a target for the treatment of diabetes (4-6). The majority of studies regarding CD26 expression are in human differentiated thyroid carcinoma (papillary thyroid carcinoma and follicular thyroid carcinoma), however little information is currently available regarding medullary thyroid carcinoma due to limited samples (7). Therefore, it remains unclear whether the GLP-1 analogue or CD26 inhibitors induce pathological changes in human thyroid C-cells. It is important to pay attention to the possible side effects of GLP-1 analogues or CD26 inhibitors on thyroid C-cells, particularly following long-term treatment with large doses.

The exact mechanisms underlying the changes to thyroid C-cells remain to be elucidated. It is important to study the side effects of long term use and/or large dosage therapy with GLP-1 analogues or CD26 inhibitors on thyroid C-cells; particularly in senior patients with diabetes or in patients with 
gastrointestinal ulcers who may receive GLP-1 analogues or CD26 inhibitors and PPIs.

The present study aimed to detect the protein expression levels of GLP-1R and CD26 in various differentiated C-cells including those from non-neoplastic thyroid tissues, C-cell hyperplasia and medullary thyroid carcinoma. An additional aim was to explore the association between GLP-1R and CD26, as well as their possible effects on thyroid C-cell tumorigenesis. It is also valuable to be aware of the side effects of incretin medicines.

\section{Materials and methods}

Human tissue processing. The samples were selected from The First Hospital (01/2004-12/2014) and The Third Hospital (01/2009-12/2014) of Harbin Medical University (Harbin, China). These samples included medullary thyroid carcinoma $(n=62 ; 59$ paraffin-embedded samples and 3 fresh frozen samples), C-cell hyperplasia $(n=20$, paraffin-embedded samples) and non-neoplastic thyroid tissue (adjacent tissue from nodular goiter) samples ( $n=7$, paraffin-embedded samples). Each sample in the study was confirmed by 2 pathologists, who were blind to the origin of the slides. Clinical pathological characteristics, including gender, age, lymph node (LN) metastasis and clinical history (diabetes history and family history of thyroid disease) were collected from the same database of the aforementioned hospitals. The survival rate was obtained from the medical records database. No patients in the study had received radiotherapy, chemotherapy or were treated with GLP-1 analogues prior to surgery. The specimens were fixed in $10 \%$ buffered formalin and embedded in paraffin. Subsequently, 3- $\mu \mathrm{m}$ sections were prepared for hematoxylin and eosin (H\&E) and immunohistochemical staining. In total, 3 fresh frozen samples underwent western blot analysis. Written informed consent was attained from the patients from whom fresh frozen tissue samples were obtained from for use in the present study. The current study was approved by The First Hospital of Harbin Medical University Medical Ethics Committee (Harbin, China; no. 201462).

Immunohistochemical staining. Immunohistochemical analysis for GLP-1R, CD26, calcitonin (CT) and Ki-67 was performed on formalin-fixed paraffin-embedded tissues. All antibodies were listed as follows: GLP-1R (cat. no. ab39072; polyclonal antibody; Abcam, Cambridge, UK), CD26 (cat. no. ab114033; monoclonal antibody; Abcam), CT (cat. no. RMA-0553; Fuzhou Maixin Biotech Co., Ltd., Fuzhou, China) and Ki-67 (cat. no. ZM-0166; Beijing Zhongshan Golden Bridge Biotechnology Co., Ltd., Beijing, China). Paraffin sections were dewaxed and incubated in $\mathrm{H}_{2} \mathrm{O}_{2}$ for $10 \mathrm{~min}$ at room temperature, then treated for $1.5 \mathrm{~min}$ at $120^{\circ} \mathrm{C}$ under high pressure $(1.2 \mathrm{P})$ in Tris-EDTA buffer ( $\mathrm{pH}$ 9.0). The sections were then allowed to cool for $5 \mathrm{~min}$ at room temperature and $15 \mathrm{~min}$ in cold water, prior to being rinsed in TBS ( $\mathrm{pH} 7.5$ ). Subsequently, 5\% normal goat serum (cat. no. ZLI-9022; Beijing Zhongshan Golden Bridge Biotechnology Co., Ltd.) was used to block heterogenetic antigens for $10 \mathrm{~min}$. Slides were incubated overnight at $4^{\circ} \mathrm{C}$ with the primary polyclonal antibody directed against GLP-1R (dilution, 1:1,000) or CD26 monoclonal antibody (dilution,
1:100); or at room temperature for $1 \mathrm{~h}$ with CT (dilution, 1:100) or Ki-67 (dilution, 1:150). Slides were washed in TBS 3 times for $10 \mathrm{~min}$ each and then incubated for $40 \mathrm{~min}$ with secondary antibody (cat. no. PV-9000; ready-to-use; Beijing Zhongshan Golden Bridge Biotechnology Co., Ltd.) at room temperature. Finally, the slides were stained with DAB (cat. no. ZLZ-9018; Beijing Zhongshan Golden Bridge Biotechnology Co., Ltd.) for 2-3 min, counterstained with hematoxylin, and then rinsed in water.

Western blot analysis. In total, 3 fresh frozen tissues samples of medullary thyroid carcinoma were tested separately using western blot analysis. Fresh-frozen tumors were cut into small pieces, mixed with lysis buffer (cat. no. P0013; Beyotime Institute of Biotechnology, Haimen, China), and centrifuged at $12,470 \mathrm{x} \mathrm{g}$ at $4^{\circ} \mathrm{C}$ for $15 \mathrm{~min}$. The pure supernatant was then collected and stored at $-80^{\circ} \mathrm{C}$. Subsequently, samples were analyzed using bicinchoninic acid assay [Bio-Rad Laboratories (Canada) Ltd., Mississauga, Canada] to quantify proteins. Each protein sample $(50-100 \mu \mathrm{g})$ was separated by $10 \%$ SDS-PAGE, blotted onto a polyvinylidene fluoride membrane to obtain the marker band and target protein bands. Membranes were incubated overnight at $4^{\circ} \mathrm{C}$ with agitation with the same primary antibodies used in the immunohistochemical analysis, as follows: GLP-1R polyclonal rabbit anti-human (dilution, 1:1,000) and CD26 monoclonal mouse anti-human (dilution, 1:500). Following the incubation, membranes were washed in bovine serum albumin (cat. no. 735094; Beyotime Institute of Biotechnology) for 10 min 3 times and incubated with a horseradish peroxidase secondary antibody (cat. no. ZB-2305; dilution, 1:1,000; Beijing Zhongshan Golden Bridge Biotechnology Co., Ltd.) at room temperature for $2 \mathrm{~h}$ with agitation. Membranes were visualized by BeyoECL Plus kits (p0018; Beyotime Institute of Biotechnology), using an enhanced chemiluminescence detection system (iBox Scientia 500 Imaging System; UVP, Inc., Upland, CA, USA).

Images and statistical analysis. Data obtained from GLP-1R and CD26 immunohistochemical staining were evaluated by the intensity and distribution of cell staining. Staining intensity was scored as follows: 0 , no staining; 1 , weak staining; 2 , moderate staining and 3 , strong staining. Staining distribution was scored as follows: $0,0 \%, 1,1-25 \% ; 2,26-50 \% ; 3,51-75 \%$ and $4,76-100 \%$. Intensity and distribution scores were then added together. If the total score was $<4$, it was considered negative. If the total score was $\geq 4$, it was considered positive. A DMI6000 microscope with Leica Application Suite image analysis software (LAS AF6000; version 4.3.0; Leica Microsystems GmbH, Wetzlar, Germany) was used to capture the images. SPSS software (version 17.0; SPSS, Inc., Chicago, IL, USA) was used to conduct statistical analysis using $\chi^{2}$ test and Spearman's rank correlation. For all statistical analyses, $\mathrm{P}<0.05$ was considered to indicate a statistically significant difference.

\section{Results}

Immunohistochemical staining. In the 59 medullary thyroid carcinoma tissues, GLP-1R membrane expression was $50.8 \%$ (30/59) (Fig. 1A) and CD26 membrane expression was 
Table I. Comparison of GLP-1R and CD26 expression among the three groups.

\begin{tabular}{lcccc}
\hline Group & GLP-1R & P-value & CD26 & P-value \\
\hline MTC & $30 / 59(50.8 \%)$ & & $23 / 59(39.0 \%)$ & \\
C-cell hyperplasia & $5 / 20(25.0 \%)$ & $0.04^{\mathrm{a}}$ & $13 / 20(65.0 \%)$ & $0.04^{\mathrm{a}}$ \\
Non-neoplasm & $0 / 7(0.0 \%)$ & $0.03^{\mathrm{b}}$ & $7 / 7(100 \%)$ & $<0.001^{\mathrm{b}}$ \\
\hline
\end{tabular}

Summary of the immunohistochemistry results. GLP-1R and CD26 immunoreactivity were compared among MTC vs. C-cell hyperplasia and MTC vs. non-neoplastic thyroid tissues. There were significant differences in expression levels among MTC, C-cell hyperplasia and non-neoplastic thyroid tissues. $\mathrm{P}<0.05$ was considered to indicate a statistically significant difference. ${ }^{\mathrm{a}} \mathrm{MTC}$ vs. C-cell hyperplasia, ${ }^{\mathrm{b}} \mathrm{MTC}$ vs. non-neoplastic thyroid tissues. GLP-1R, glucagon-like peptide-1 receptor; CD, cluster of differentiation; MTC, medullary thyroid cancer.

$39.0 \%$ (23/59) (Fig. 1B). A similar trend to that determined using immunohistochemistry was also detected in fresh frozen medullary thyroid carcinoma samples via western blot analysis (Fig. 1C). In the $20 \mathrm{C}$-cell hyperplasia samples, GLP-1R membrane expression was $25.0 \%$ (5/20) (Fig. 2A) and CD26 membrane expression was $65.0 \%$ (13/20) (Fig. 2B). In the 7 non-neoplastic thyroid tissues, GLP-1R membrane expression was $0.0 \%(0 / 7)$ (Fig. 3A) and CD26 membrane expression was $100 \%$ (7/7) (Fig. 3B). There were significant differences in GLP-1R and CD26 expression among medullary thyroid carcinoma, C-cell hyperplasia and non-neoplastic thyroid tissues (Table I).

Clinical characteristics. The associations between the 2 markers and clinical pathological characteristics were analyzed. Tests on clinical pathological characteristics (age, gender, LN metastasis, and diabetes history or family history of thyroid disease) were performed separately. GLP-1R exhibited a significant correlation with age in the medullary thyroid carcinoma group ( $<30,30-50$ and $\geq 50$ years). However, there were no significant differences in gender, LN metastasis, diabetes history or family history of thyroid disease (Table II). There was no correlation between CD26 and any of the aforementioned clinical characteristics.

Association between GLP-1R and CD26. There was a significantly negative correlation between GLP-1R and CD26 expression in medullary thyroid carcinoma, $\mathrm{C}$-cell hyperplasia and non-neoplastic samples (Table III).

\section{Discussion}

Incretin medicines, including GLP-1 analogues and CD26 inhibitors, have been used to treat patients with type 2 diabetes. Other than providing a glucose-dependent method of promoting insulin secretion and inhibiting glucagon secretion, they have many benefits, including delaying gastric emptying, lowering the risk of hypoglycemia, weight reduction, and cardiovascular and neural protection. Although these medicines have shown success in the therapeutic market, the possible side effects on human thyroid C-cells should not be ignored. Previous studies have demonstrated that in rodents, long-term use and/or large doses of GLP-1 analogues may induce thyroid C-cell hyperplasia, hypercalcitoninemia and even medullary carcinoma $(2,3,8)$. However, several clinical trials have indicated
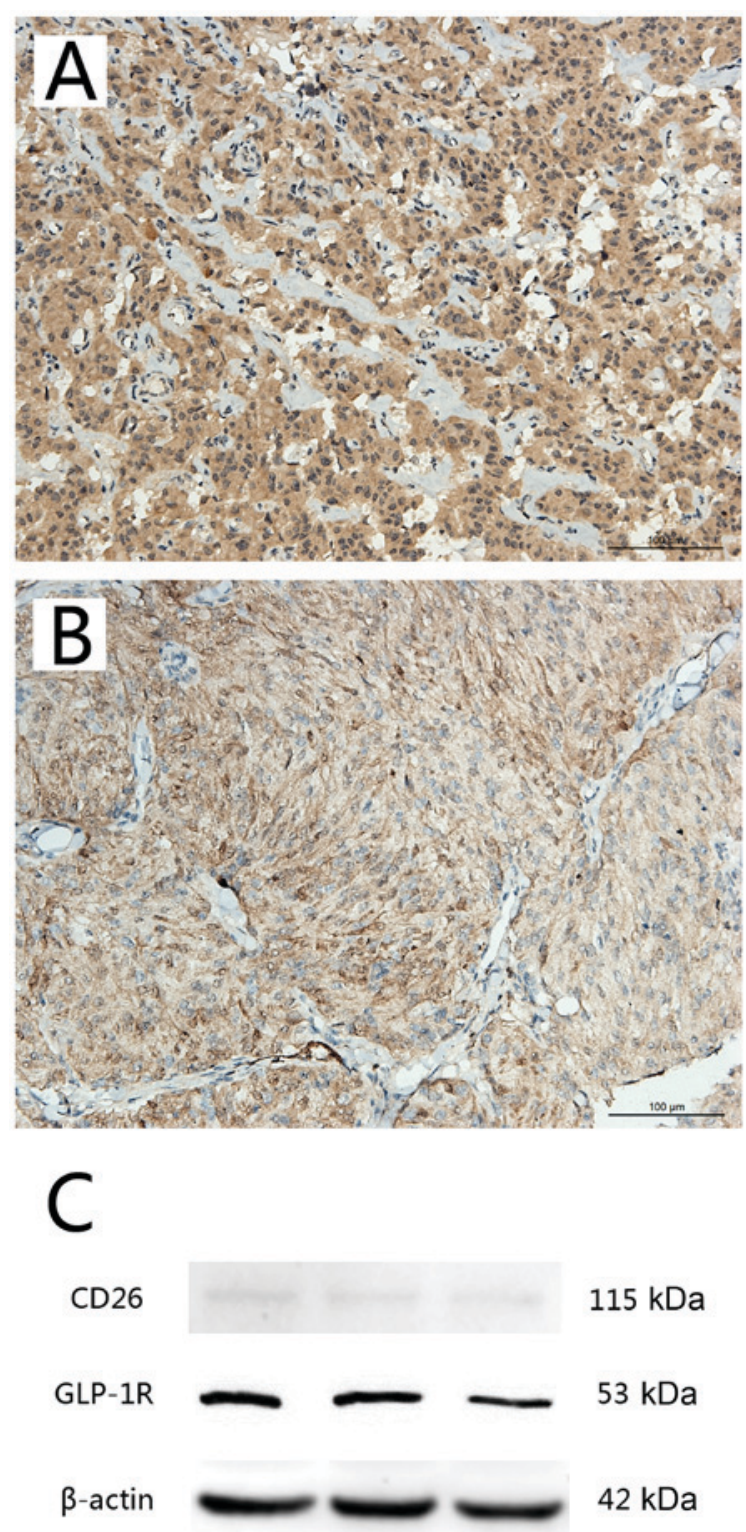

Figure 1. Expression of GLP-1R and CD26 in human medullary thyroid carcinoma. (A) Immunoreactive staining of GLP-1R in human medullary thyroid carcinoma. (B) Immunoreactive staining of CD26 in human medullary thyroid carcinoma. (C) Detection of GLP-1R with ab39072 (53-kDa band) and CD26 with ab28340 antibodies (115-kDa band) in lysates of fresh frozen medullary thyroid carcinoma samples (3 separate medullary thyroid carcinoma samples). $\beta$-actin (115-kDa band) was used as the loading control. Scale bar, $100 \mu \mathrm{m}$. GLP-1R, glucagon-like peptide-1 receptor; CD, cluster of differentiation. 

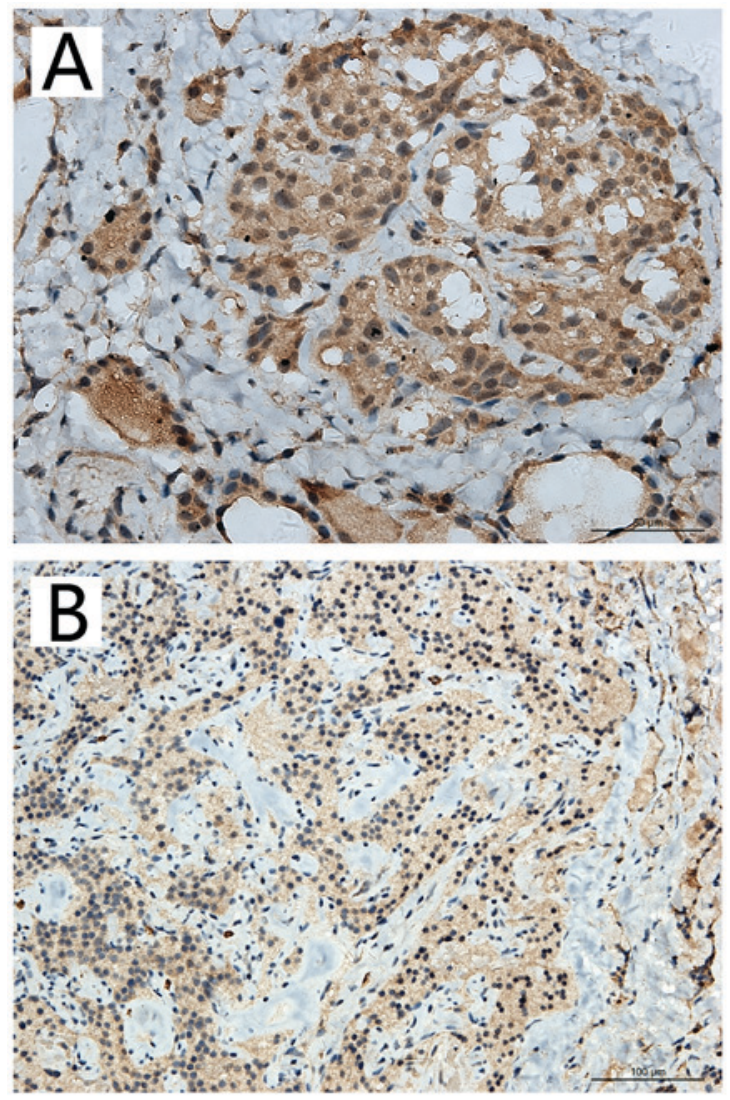

Figure 2. Expression of GLP-1R and CD26 in human thyroid C-cell hyperplasia. (A) Immunoreactive staining of GLP-1R in human thyroid C-cell hyperplasia. Scale bar, $50 \mu \mathrm{m}$. (B) Immunoreactive staining of CD26 in human thyroid C-cell hyperplasia. Scale bar, $100 \mu \mathrm{m}$. GLP-1R, glucagon-like peptide-1 receptor; $\mathrm{CD}$, cluster of differentiation.

no significant side effects on the function or morphology of human C-cells $(2,3,9)$. Questions remain regarding the side effects of GLP-1 analogues on C-cells. Waser et al (10) reported that $27 \%$ of medullar thyroid carcinoma cells were immunoreactive for GLP-1R (10). However, there is a shortage of studies investigating patients with diabetes who have been treated with GLP-1 analogues for a prolonged period of time. Furthermore, $\mathrm{C}$-cell abnormalities are rare and asymptomatic. In addition to the GLP-1R pathway, several other factors may influence C-cells, including gastrin, glucagon and calcium. The coexistence of common diseases may lead to complex drug requirements. For example, combination therapy with GLP-1 analogues and PPIs is becoming a real possibility (11), despite their effects on C-cells remaining unclear. Therefore, $\mathrm{C}$-cell safety is a matter of concern.

CD26 inhibitors are another point of controversy, since they may suppress T-lymphocytes, induce infection and lead to a slight decrease in lymphocyte count (12). Although there is no evidence to suggest that a CD26 inhibitor affects the immune system (13), a previous analysis that assessed the safety and tolerability of sitagliptin (a drug in the class of CD26 inhibitors) indicated a trend toward an increased risk of neoplasm (14). Other than its effects on the degradation of incretins, there are several other target peptides degraded by CD26. It is generally considered that CD26 is involved in immune regulation, cell differentiation and tumor biology. It remains to be determined whether CD26 inhibitors may influence thyroid C-cells.
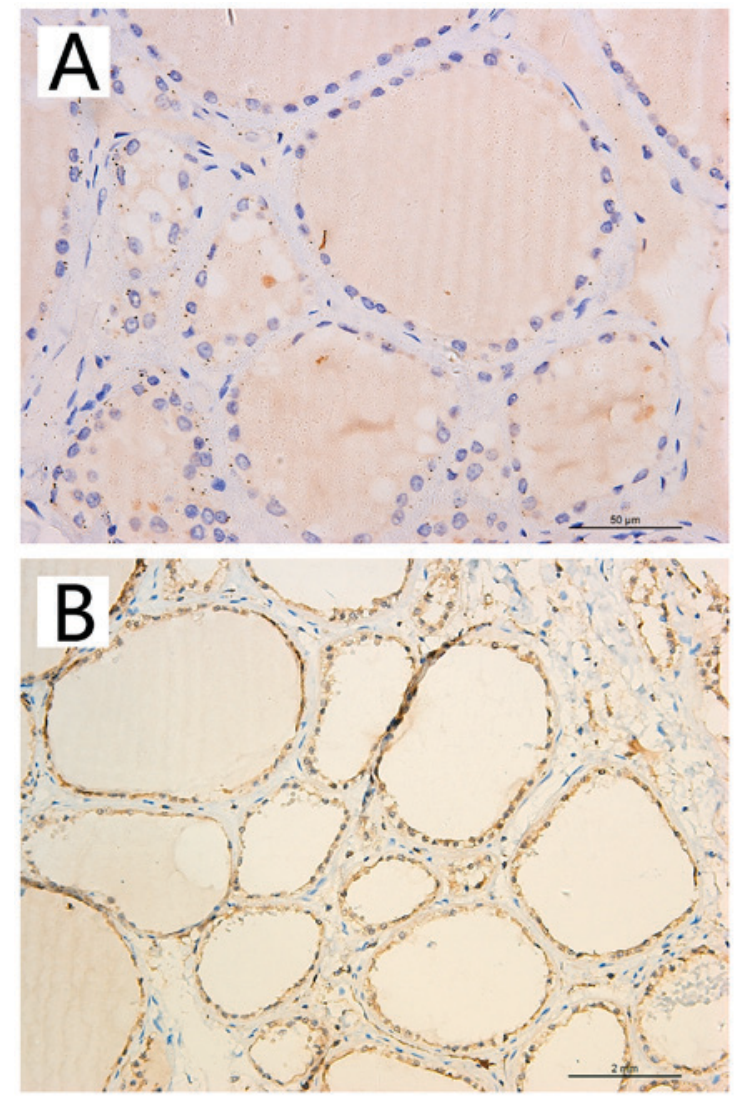

Figure 3. Expression of GLP-1R and CD26 in non-neoplastic human thyroid tissues. (A) Immunoreactive staining of GLP-1R in non-neoplastic human thyroid tissues. Scale bar, $50 \mu \mathrm{m}$. (B) Immunoreactive staining for CD26 in non-neoplastic human thyroid tissues. Scale bar, $2 \mathrm{~mm}$. GLP-1R, glucagon-like peptide-1 receptor; $\mathrm{CD}$, cluster of differentiation.

Therefore, there are additional studies required prior to the safety of incretin therapy being confirmed. It is also important to pay more attention to the potential side effects on human thyroid C-cells during long-term treatment or large dosage treatment with GLP-1 analogues or CD26 inhibitors.

The present study focused on the possible side effects of GLP-1 analogues and CD26 inhibitors on human thyroid C-cells by detecting the expression levels of GLP-1R and CD26 in thyroid C-cells from non-neoplastic thyroid, C-cell hyperplasia and medullary thyroid carcinoma tissues. The effects of GLP-1 analogues and CD26 inhibitors, which target GLP-1R and CD26 expression, on thyroid C-cells were also indirectly investigated. To the best of our knowledge, little is known about this from similar studies. In addition, the present study is the first, to the best of our knowledge, to detect the expression of GLP-1R and CD26 in a large number of human medullary thyroid carcinoma samples in order to determine the coexpression of GLP-1R and CD26.

At present, little is known regarding the expression of GLP-1R in tumors and non-neoplastic tissues. Previous studies have detected GLP-1R expression in the human thyroid using autoradiography and mRNA analysis (15-17). The majority of studies were carried out in cell-lines in vitro. To date, there has been no definite information regarding GLP-1R in human medullary thyroid carcinoma. GLP-1R immunoreactivity has previously been detected in $91.7 \%$ of medullary thyroid carcinoma samples, $100 \%$ of C-cell hyperplasia samples and 
Table II. Association of GLP-1R or CD26 with clinical characteristics in medullary thyroid carcinoma.

\begin{tabular}{|c|c|c|c|c|c|c|c|}
\hline \multirow[b]{2}{*}{ Clinical characteristics } & \multirow[b]{2}{*}{$\mathrm{n}$} & \multicolumn{3}{|c|}{ GLP-1R } & \multicolumn{3}{|c|}{$\mathrm{CD} 26$} \\
\hline & & Positive & Negative & P-value & Positive & Negative & P-value \\
\hline \multicolumn{8}{|l|}{ Age, years } \\
\hline$\leq 30$ & 5 & 4 & 1 & & 1 & 4 & \\
\hline $30-50$ & 29 & 10 & 19 & & 13 & 16 & \\
\hline$\geq 50$ & 25 & 16 & 9 & 0.034 & 9 & 16 & 0.531 \\
\hline \multicolumn{8}{|l|}{ Gender } \\
\hline Male & 17 & 9 & 8 & & 7 & 10 & \\
\hline Female & 42 & 21 & 21 & 0.838 & 16 & 26 & 0.826 \\
\hline \multicolumn{8}{|l|}{ LN metastasis } \\
\hline Yes & 26 & 14 & 12 & & 12 & 14 & \\
\hline No & 33 & 16 & 17 & 0.683 & 12 & 21 & 0.447 \\
\hline \multicolumn{8}{|l|}{ Diabetes history } \\
\hline Yes & 3 & 1 & 2 & & 2 & 1 & \\
\hline No & 56 & 29 & 27 & 0.976 & 22 & 34 & 0.736 \\
\hline \multicolumn{8}{|l|}{ Family history } \\
\hline Yes & 15 & 8 & 7 & & 6 & 9 & \\
\hline No & 44 & 22 & 22 & 0.824 & 17 & 27 & 0.925 \\
\hline
\end{tabular}

Summary of associations between GLP-1R or CD26 and clinical characteristics in medullary thyroid carcinoma. GLP-1R exhibited a significant correlation with age. $\mathrm{P}<0.05$ was considered to indicate a statistically significant difference. GLP-1R, glucagon-like peptide-1 receptor; $\mathrm{CD}$, cluster of differentiation; LN, lymph node.

Table III. Correlations between GLP-1R, CD26 and Ki-67.

\begin{tabular}{lrc}
\hline Protein & CD26 & Ki-67 \\
\hline GLP-1R & & \\
R-value & -0.303 & 0.198 \\
P-value & 0.021 & 0.466 \\
CD26 & & \\
R-value & & 0.104 \\
P-value & & 0.439 \\
\hline
\end{tabular}

Summary of the correlations among GLP-1R, CD26 and Ki-67 protein expression. There was a significant negative correlation between GLP-1R and CD26 expression. $\mathrm{P}<0.05$ was considered to indicate a statistically significant difference. GLP-1R, glucagon-like peptide-1 receptor; $\mathrm{CD}$, cluster of differentiation.

$33.3 \%$ of normal thyroid tissue (18), using the same polyclonal antibody as used in the present study (ab39072). The present study detected similar trends to previous studies, which unequivocally suggests that GLP-1R is present on C-cells. Furthermore, GLP-1R immunoreactivity has been detected in papillary thyroid carcinoma $(9,18,19)$. In tumor tissue, GLP-1R is expressed at a higher level than in non-neoplastic tissues, which may induce tumorigenesis. GLP-1 may also activate the p38 mitogen-activated protein kinase (p38 MAPK) pathway phosphorylation by inducing production of cyclic adenosine monophosphate (cAMP) (20) and indirect evidence suggests that an alternative GLP-1R is involved in this process (21). Therefore, it is necessary to pay more attention to the potential side effects on the thyroid among the patients subsequent to taking GLP-1 analogues. For the present study, it was essential to study the risk prospectively.

CD26 is a multifunctional cell surface protein that is widely expressed in almost all human organs, particularly on T lymphocytes (22). At present, the majority of studies into CD26 expression have been confined to follicular differentiated thyroid carcinoma (23-25). Conversely, there is little information regarding medullary thyroid carcinoma, taken from limited samples. The results of previous study on a limited number of samples of medullary thyroid carcinoma tissue demonstrated that there was no CD26 expression (23). CD26 exerts an important effect in tumor biology, and serves as a marker in various types of cancer. In differentiated thyroid carcinomas, the mean positive $\mathrm{Ki}-67$ cell rate has been reported to be lower in CD26-positive tissues compared with in CD26-negative tissues (24). However, the present study did not identify an association between CD26 and $\mathrm{Ki}-67$ expression in medullary thyroid carcinoma. In the present study, CD26 was expressed at a higher level in non-neoplastic thyroid tissues compared with in neoplastic tissues, which may inhibit tumorigenesis. It has previously been reported that CD26 expression may potentially reverse tumor differentiation and suppress the invasion of tumors via the p38 pathway (26). Treatments targeting CD26 may be an effective approach for selected tumors. However, whether CD26 inhibitors increase the risk of cancer remains unknown, and requires additional study. 
The present study is the first, to the best of our knowledge, to demonstrate that GLP-1R expression is associated with the age of patients with medullary thyroid carcinoma; this result may indicate that incretin therapy is less safe in the elderly population. A previous study demonstrated that CD26 was associated with age; negative expression was detected in normal infants, whereas positive expression was detected in older individuals to varying degrees (24). However, the present study did not attain the same result, which may be due to the age range of the samples. In addition, CD26 was not associated with any other characteristic tested in the present study. GLP-1R expression was negatively correlated with CD26 expression. The possible reasons are as follows: In the human body, GLP-1R has been reported to be the substrate for circulating CD26 (27). GLP-1R is the receptor of the substrate GLP-1, and CD26 is the hydrolase. CD26 is a multifunctional cell surface protein that is predominantly expressed on $\mathrm{T}$ lymphocytes, and serves a significant role in tumor immunity. CD26 has a role in tumor immunity regulation. The p38 MAPK signaling pathway is a classical cell signaling transduction pathway and is associated with tumor progression. GLP-1R is a promoter of this signaling pathway, thus serving a role in tumor progression. However, CD26 is an inhibitor of the p38 MAPK signaling pathway and serves a role in tumor immunity $(21,26,28)$. Therefore, GLP-1R and CD26 exert opposing effects, which has also been verified in the present study.

There remain limitations to the present study. Although GLP-1R expression was widely distributed in the human thyroid, the present study could not discriminate the functional receptors. Only functional receptors are able to exert effects. In the present study, paraffin-embedded sections were selected; however, cAMP production could not be specifically measured. Usually, cAMP is deemed as an index of determining whether the receptor is functional or not. The production of cAMP is the output of GLP-1 binding to GLP-1R (29). Furthermore, the molecular mechanism underlying the changes to thyroid $\mathrm{C}$-cells requires further study. In addition, the present study tracked the prognosis of all 59 patients with medullary thyroid carcinoma. However, there was no statistical significance in the survival analysis.

In conclusion, although incretin-based therapy may be associated with medullary thyroid carcinoma, the benefits may outweigh the potential cancer risk in patients with type 2 diabetes.

\section{Acknowledgements}

The authors would like to thank the Department of Pathology, The First Hospital of Harbin Medical University and the Department of Pathology, The Third Hospital of Harbin Medical University for providing the thyroid samples. The authors would also like to thank Professor Xiaomin Liu for his assistance and guidance, and our technologist Ms. Yunhe Gu for the immunohistochemical staining.

\section{References}

1. Baggio LL and Drucker DJ: Biology of incretins: GLP-1 and GIP. Gastroenterology 132: 2131-2157, 2007.

2. Bjerre Knudsen L, Madsen LW, Andersen S, Almholt K, de Boer AS, Drucker DJ, Gotfredsen C, Egerod FL, Hegelund AC, Jacobsen $\mathrm{H}$, et al: Glucagon-like peptide-1 receptor agonists activate rodent thyroid c-cells causing calcitonin release and c-cell proliferation. Endocrinology 151: 1473-1486, 2010.
3. Madsen LW, Knauf JA, Gotfredsen C, Pilling A, Sjögren I, Andersen S, Andersen L, de Boer AS, Manova K, Barlas A, et al: GLP-1 receptor agonists and the thyroid: C-cell effects in mice are mediated via the GLP-1 receptor and not associated with RET activation. Endocrinology 153: 1538-1547, 2012.

4. Hafler DA, Fox DA, Manning ME, Schlossman SF, Reinherz EL and Weiner HL: In vivo activated T lymphocytes in the peripheral blood and cerebrospinal fluid of patients with multiple sclerosis. N Engl J Med 312: 1405-1411, 1985.

5. Hildebrandt M, Rose M, Rüter J, Salama A, Mönnikes H and Klapp BF: Dipeptidyl peptidase IV (DP IV, CD26) in patients with inflammatory bowel disease. Scand J Gastroenterol 36: 1067-1072, 2001.

6. Gotoh H, Hagihara M, Nagatsu T, Iwata H and Miura T: Activities of dipeptidyl peptidase II and dipeptidyl peptidase IV in synovial fluid from patients with rheumatoid arthritis and osteoarthritis. Clin Chem 35: 1016-1018, 1989.

7. Cordero OJ, Salgado FJ and Nogueira M: On the origin of serum CD26 and its altered concentration in cancer patients. Cancer Immunol Immunother 58: 1723-1747, 2009.

8. Parks $\mathrm{M}$ and Rosebraugh C: Weighing risks and benefits of liraglutide -The FDA's review of a new antidiabetic therapy. N Engl J Med 362: 774-777, 2010.

9. Gier B, Butler PC, Lai CK, Kirakossian D, DeNicola MM and Yeh MW: Glucagon like peptide-1 receptor expression in the human thyroid gland. J Clin Endocrinol Metab 97: 121-131, 2012.

10. Waser B, Beetschen K, Pellegata NS and Reubi JC: Incretin receptors in non-neoplastic and neoplastic thyroid $\mathrm{C}$ cells in rodents and humans: Relevance for incretin-based diabetes therapy. Neuroendocrinology 94: 291-301, 2011.

11. Cao Y and Liu XM: Should we still be concerned about the potential side effects of glucagon-like peptide-1 receptor agonists on thyroid C cells? Endocrine 48: 47-52, 2015.

12. Yazbeck R, Howarth GS and Abbott CA: Dipeptidyl peptidase inhibitors, an emerging drug class for inflammatory disease? Trends Pharmacol Sci 30: 600-607, 2009.

13. Ali S and Fonseca V: Saxagliptin overview: Special focus on safety and adverse effects. Expert Opin. Drug Saf 12: 103-109, 2013.

14. Williams-Herman D, Engel SS, Round E, Johnson J, Golm GT, Guo H, Musser BJ, Davies MJ, Kaufman KD and Goldstein BJ: Safety and tolerability of sitagliptin in clinical studies: A pooled analysis of data from 10,246 patients with type 2 diabetes. BMC Endocr Disord 10: 7, 2010.

15. Wei Y and Mojsov S: Tissue-specific expression of the human receptor for glucagonlike peptide-I: Brain, heart and pancreatic forms have the same deduced amino acid sequences. FEBS Lett 358: 219-224, 1995.

16. Satoh F, Beak SA, Small CJ, Falzon M, Ghatei MA, Bloom SR and Smith DM: Characterization of human and rat glucagonlike peptide-1 receptors in the neurointermediate lobe: Lack of coupling to either stimulation or inhibition of adenylyl cyclase. Endocrinology 141: 1301-1309, 2000.

17. Vara E, Arias-Díaz J, Garcia C, Balibrea JL and Blázquez E: Glucagon-like peptide-1(7-36) amide stimulates surfactant secretion in human type II pneumocytes. Am J Respir Crit Care Med 163: 840-846, 2001.

18. Mayo KE, Miller LJ, Bataille D, Dalle S, Göke B, Thorens B and Drucker DJ: International Union of Pharmacology. XXXV. The glucagon receptor family. Pharmacol Rev 55: 167-194, 2003.

19. Jung MJ and Kwon SK: Expression of glucagon-like peptide-1 receptor in papillary thyroid carcinoma and its clinicopathologic significance. Endocrinol Metab (Seoul) 29: 536-544, 2014.

20. Kwon G, Marshall CA, Pappan KL, Remedi MS and McDaniel ML: Signalling elements involved in the metabolic regulation of mTOR by nutrients, incretins, and growth factors in islets. Diabetes 53 (Suppl 3): S225-S232, 2004.

21. Ligumsky H, Wolf I, Israeli S, Haimsohn M, Ferber S, Karasik A, Kaufman B and Rubinek T: The peptide-hormone glucagon-like peptide-1 activates cAMP and inhibits growth of breast cancer cells. Breast Cancer Res Treat 132: 449-461, 2012.

22. Mentlein R: Dipeptidyl-peptidase IV (CD26)-role in the inactivation of regulatory peptides. Regul Pept 85: 9-24, 1999.

23. Aratake Y, Umeki K, Kiyoyama K, Hinoura Y, Sato S, Ohno A, Kuribayashi T, Hirai K, Nabeshima K and Kotani T: Diagnostic utility of galectin-3 and CD26/DPPIV as preoperative diagnostic markers for thyroid nodules. Diagn Cytopathol 26: 366-372, 2002.

24. Lima MA, Gontijo VA and Schmitt FC: CD26 (Dipeptidyl Aminopeptidase IV) expression in normal and diseased human thyroid glands. Endocr Pathol 9: 43-52, 1998. 
25. de Lima MA and Schmitt FC: Dipeptidyl aminopeptidase IV (CD26) expression in thyroid tissues. Diagn Cytopathol 21: 78, 1999.

26. Wesley UV, Albino AP, Tiwari S and Houghton AN: A role for dipeptidyl peptidase IV in suppressing the malignant phenotype of melanocytic cells. J Exp Med 190: 311-322, 1999.

27. Peters A: Incretin-based therapies: Review of current clinical trial data. Am J Med 123 (3 Suppl): S28-S37, 2010.
28. Sato T, Yamochi T, Yamochi T, Aytac U, Ohnuma K, McKee KS, Morimoto $\mathrm{C}$ and Dang NH: CD26 regulates p38 mitogen-activated protein kinase-dependent phosphorylation of integrin betal, adhesion to extracellular matrix and tumorigenicity of T-anaplastic large cell lymphoma Karpas 299. Cancer Res 65: 6950-6956, 2005

29. Vangoitsenhoven R, Mathieu C and Van der Schueren B: GLP1 and cancer: Friend or foe?. Endocr Relat Cancer 19: F77-F88, 2012. 